\title{
PEMBUATAN SERBUK INSTAN KUNYIT PUTIH (Curcuma zedoaria (Bergius) Roscoe.) DAN KACANG MERAH (Phaseolus vulgaris L.) SEBAGAI ANTIOKSIDAN
}

\author{
Salma Sabilah" ${ }^{*}$, Susi Andriani2 ${ }^{2}$, Suharti $^{3}$ \\ 1,2,3 Sekolah Tinggi Ilmu Kesehatan Holistik
}

*Korespondensi: Jl. Veteran No. 272 Cisereuh Purwakarta, Email: salmasabilah86@gmail.com

\begin{abstract}
ABSTRAK
Latar Belakang: Radikal bebas dapat memicu penyebab beberapa penyakit seperti kanker, gangguan fungsi ginjal, serangan jantung dan katarak. Antioksidan alami dapat membantu menetralisir radikal bebas dalam tubuh manusia. Serbuk instan kunyit putih dan kacang merah ini memiliki kandungan kaya akan antioksidan karena kunyit putih dan kacang merah mengandung polifenol yang dikenal sebagai antioksidan.

Tujuan Penelitian: Penelitian ini bertujuan untuk membuat sediaan serbuk instan kunyit putih (Curcuma zedoaria) dan kacang merah (Phaseolus vulgaris L.) sebagai antioksidan serta mencari formulasi terbaik berdasarkar uji organoleptik selama 3 minggu.
\end{abstract}

Metode: Disain penelitian ini adalah penelitian tindakan, yang terdiri dari tahap perencanan, pelaksanaan, pengamatan dan refleksi atau evaluasi. Penelitian ini dibagi menjadi dua tahap yaitu tahap pertama, proses pembuatan sedian serbuk instan dengan metode kristalisasi dan tahap kedua, uji organoleptik sediaan serbuk instan.

Hasil: Hasil penelitian dari pembuatan serbuk instan kunyit putih dan kacang merah menghasilkan jumlah yang berbeda-beda yaitu FI 164 gram, FII 361 gram dan FIII 541 gram. Hasil uji organoleptik dari ketiga sampel menunjukan tidak adanya perubahan yang signifikan dalam hal bau, bentuk, rasa dan warna. Formula terbaik setelah uji organoleptik selama 3 minggu yaitu FII 1:1 (sari $400 \mathrm{ml}$ : gula $400 \mathrm{~g}$ ).

Simpulan: Penelitian ini menunjukan bahwa serbuk instan kunyit putih dan kacang merah yang memiliki formulasi terbaik berdasarkan uji organoleptik selama 3 minggu yaitu pada FII 1:1 (sari $400 \mathrm{ml}$ : gula $400 \mathrm{~g}$ ).

Kata kunci: antioksidan, kacang merah, kunyit putih, serbuk instan.

\begin{abstract}
Background: Free radicals can trigger the causes of such diseases as cancer, kidney disorders, heart attacks and cataracts. Antioxidants can help neutralize free radicals in the human body. Instant powder white tumeric and red beans are rich in antioxidant deposits because white tumeric and red beans contain the polyphenol known as antioxidants.

Objective: The aim of this study is to make available existing instant powder white tumeric (Curcuma zedoaria) and red beans (Phaseolus vulgaris L.) as antioxidants and search for the best formulation based on organoleptic test in three weeks.

Method: This design of this study is action research, which consists of stages planning, implementation, observation and reflection or evaluation. The study is divided into the first two stages, the process by which sedimentation is produced criztallization methods and phase two, availability of pollen organoleptic test instan powder.

Results: The results of study of the production of white tumeric and red beans instant powder have produced varying quantities of FI 164 grams, FII 361 grams and FIII 541 grams. The results of all three samples organoleptic test showed no significant changes in smell, shape, taste and color. The best formula after three weeks of organoleptic test is FII 1:1 (essence $400 \mathrm{ml}$ : sugar $400 \mathrm{~g}$ ).

Conclusion: The study shows that white tumeric and red beans instant powder that have the best formulation based on three weeks of organoleptic testing on FII 1:1 (essence 400 $\mathrm{ml}$ : sugar $400 \mathrm{~g}$ ).
\end{abstract}

Keywords: antioxidant, red beans, white turmeric, instant powder. 


\section{PENDAHULUAN}

Radikal bebas merupakan senyawa yang mengandung elektron tak berpasangan, yang dapat menyebabkan ketidak seimbangan molekul radikal yang dapat bereaksi dengan molekul lain dan membentuk radikal baru. Radikal bebas dapat terpapar di mana saja dan kapan saja bahkan tanpa disadari kita dapat terpapar radikal bebas terus menerus, bisa dari polusi udara, asap rokok, sinar ultra violet dan masih banyak lagi. Ada beberapa penyakit kronis yang disebabkan oleh radikal bebas diantaranya kanker, gangguan fungsi ginjal, serangan jantung dan katarak. Pencegahannya yaitu diperlukannya antioksidan [1].

Antioksidan adalah senyawa untuk menstabilkan radikal bebas dalam tubuh dengan melengkapi kekurangan elektron dan memiliki fungsi untuk melindungi tubuh akibat oksidasi radikal bebas [2]. Antioksidan alami dapat ditemukan diberbagai tanaman, baik itu buah, sayur, kacang-kacangan, rimpang dan tanaman obat lainnya. Salah satu rimpang yang memiliki antioksidan yaitu kunyit putih (Curcuma zedoaria). Melihat data empiris mengenai penggunaan kunyit putih (Curcuma zedoaria) dimasyarakat, khususnya orang tua jaman dulu di daerah kampung Baranangsiang, Kelurahan Sindangkasih, Kecamatan Purwakarta, Kabupaten Purwakarta bahwa kunyit putih digunakan untuk melancarkan menstruasi dan digunakan untuk membersihkan rahim pasca operasi miom.

Senyawa antioksidan yang terkandung dalam C. zedoaria salah satunya yaitu polifenol. Polifenol dikenal dengan antioksidan yang kuat dapat mencegah pembentukan radikal bebas. Selain sebagai antioksidan, rimpang C. zedoaria memiliki manfaat sebagai obat, diantaranya antiinflamasi, anti kanker dan anti mikroba [3].

Kacang merah (Phaseolus vulgaris
L.) juga memiliki manfaat sebagai
antioksidan karena mengandung senyawa
polifenol yang berbentuk prosianidin
sekitar $7-8 \%$ yang banyak ditemukan
dibagian kulit kacang merah [2]. Kacang
merah memiliki aktivitas antioksidan

karena mengandung asam fenolik, flavonoid dan tanin. Aktivitas antioksidan, terutama pada senyawa polifenol memiliki fungsi penting dalam menetralisir radikal bebas [4].

Produk pangan yang dikehendaki masyarakat saaat ini tidak hanya mempertimbangkan khasiat tetapi juga melihat kepraktisannya. Minuman serbuk instan ini merupakan salah satu produk siap saji, minuman yang berbentuk serbuk kering, mudah larut dalam air, praktis dalam penyajian dan lebih awet atau memiliki waktu simpan yang relatif lama karena kadar air yang rendah, sehingga memungkinkan mikroba tidak tumbuh dalam sediaan [5].

Pada penelitian sebelumnya, sudah ada penelitian tentang pembuatan serbuk instan kunyit putih sebagai antioksidan [6], akan tetapi yang dibuat hanya menggunakan satu bahan. Sehingga, pada penelitian saat ini pembuatan serbuk instan menggunakan kunyit putih dan penambahan kacang merah yang memiliki khasiat sebagai antioksidan.

\section{METODE PENELITIAN}

Penelitian ini menggunakan disain penelitian tindakan (action research). Penelitian tindakan memiliki siklus yang terus menerus yaitu perencanaan, pengambilan tindakan (pelaksanaan), dan evaluasi atas tindakan. Siklus ini terus berlanjut sampai ditemukan tindakan yang efektif dan efisien [7].

Penelitian ini dibagi menjadi dua tahap yaitu tahap pertama, proses pembuatan sedian serbuk instan dengan metode kristalisasi dan tahap kedua, uji organoleptik sediaan serbuk instan. 
Tabel 1. Formulasi Sediaan Serbuk Instan

\begin{tabular}{cccc}
\hline Bahan & I & $\begin{array}{c}\text { Formula } \\
\text { II }\end{array}$ & III \\
\hline Sari kunyit & $200 \mathrm{ml}$ & $200 \mathrm{ml}$ & $200 \mathrm{ml}$ \\
putih & & & \\
(Curcuma & & & \\
zedoaria) & & & \\
Sari kacang & $200 \mathrm{ml}$ & $200 \mathrm{ml}$ & $200 \mathrm{ml}$ \\
merah & & & \\
(Phaseolus & & & \\
vulgaris L.) & & & \\
Gula pasir & $200 \mathrm{~g}$ & $400 \mathrm{~g}$ & $600 \mathrm{~g}$ \\
Perbandingan & $1: 1 / 2$ & $1: 1$ & $1: 1 \frac{1}{2}$ \\
\hline & & & \\
\hline
\end{tabular}

Tabel 1 menunjukkan formulasi sediaan serbuk instan, formulasi yang dibuat yaitu tiga formulasi dengan perbandingan $1: 1 / 2,1: 1$ dan $1: 1 \frac{1}{2}$. Pembeda pada formulasi ini yaitu jumlah gula pasir yang digunakan. Formulasi ini yang digunakan dengan formula 2:1 (sari rimpang dan sari kacang merah banding gula) [6].

\section{HASIL PENELITIAN}

\section{Hasil Pembuatan Serbuk Instan}

Pada proses pembuatan serbuk instan ini, kunyit putih dan kacang merah didapatkan langsung dari pasar tradisional Purwakarta. Kunyit putih yang digunakan yaitu kunyit putih yang bentuknya masih segar. Pemilihan kacang merah diambil yang masih segar berwarna merah agak keputihan. Setelah penyortiran, bahan baku dicuci dengan air mengalir, dibersihkan tanah atau kotoran yang menempel pada bahan baku, lalu ditiriskan diwadah yang berlubang seperti saringan agar bebas dari air. Proses selanjutnya yaitu proses penimbangan bahan baku.

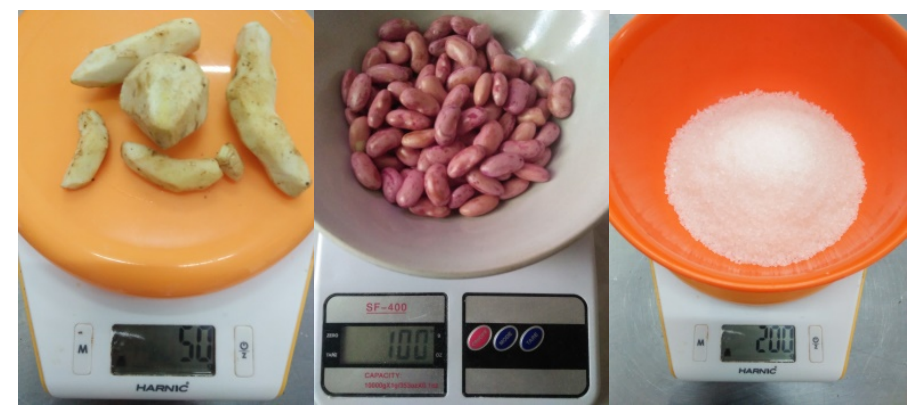

Gambar 1. Penimbangan Bahan Baku

Proses selanjutnya yaitu pembuatan sari kunyit putih dan kacang merah. Pada pembuatan sari kunyit putih, ambil sebanyak 50 gram lalu hancurkan menggunakan blender dengan air sebanyak $200 \mathrm{ml}$, setelah diblender pisahkan dengan ampasnya dan ambil sarinya. Pada pembuatan sari kacang merah, ambil sebanyak 100 gram lalu rebus kurang lebih 10 menit, setelah itu kacang merah diblender dengan air sebanyak $200 \mathrm{ml}$, setelah itu ambil sarinya.

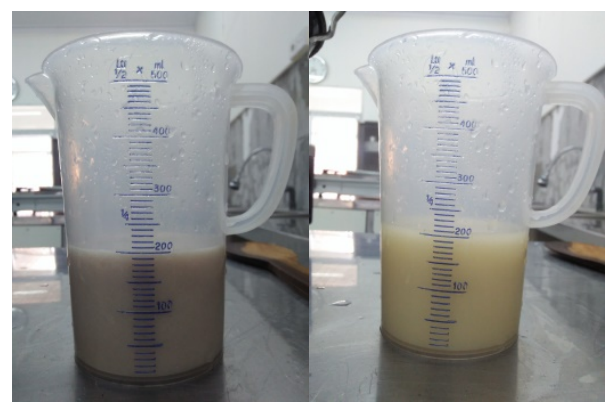

Gambar 2. Sari Kunyit Putih dan Kacang Merah 
Pada pembuatan serbuk instan kunyit putih dan kacang merah dengan perbandingan $1: 1 / 2$ (sari $400 \mathrm{ml}$ : gula 200 g), ambil $200 \mathrm{ml}$ sari kunyit putih, $200 \mathrm{ml}$ sari kacang merah dan gula pasir 200 gram, masak di dalam wajan dengan api kecil sambil terus diaduk-aduk, sampai mengkristal kemudian angkat dan dinginkan. Gumpalan kristal dihancurkan dengan blender sampai berbentuk butiran halus.

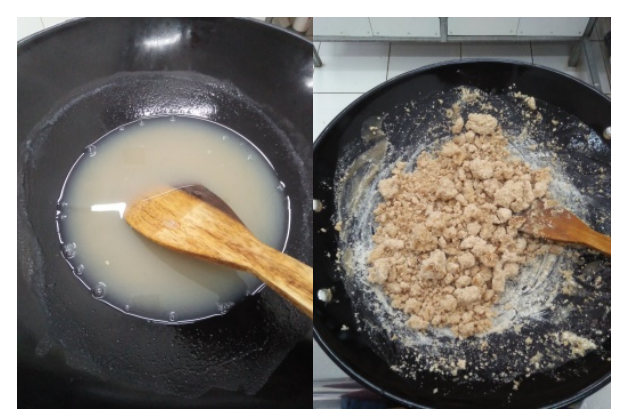

Gambar 3. Pembuatan Serbuk Instan

Butiran-butiran tersebut kemudian diayak menggunakan alat pengayak dengan lolosan ayakan 100 mesh agar kehalusannya sama. Proses pembuatan diulang pada formulasi kedua dan ketiga dengan perbandingan $1: 1$ dan 1:11/2.

Tabel 2. Hasil Pembuatan Serbuk Instan Kunyit Putih dan Kacang Merah

\begin{tabular}{ccc}
\hline Formulasi & $\begin{array}{c}\text { Bahan } \\
\text { mentah }\end{array}$ & $\begin{array}{c}\text { Hasil serbuk } \\
\text { instan }\end{array}$ \\
\hline I & $1: 1 / 2$ & $164 \mathrm{~g}$ \\
& $($ sari $400 \mathrm{ml}:$ & \\
gula $200 \mathrm{~g}$ ) & \\
II & $1: 1$ & $361 \mathrm{~g}$ \\
& $($ sari $400 \mathrm{ml}:$ & \\
& gula $400 \mathrm{~g}$ ) & \\
$1: 1 \frac{1}{2}$ & $541 \mathrm{~g}$ \\
III & (sari $400 \mathrm{ml}:$ & \\
& gula $600 \mathrm{~g}$ ) & \\
&
\end{tabular}

Pada Tabel 2. menunjukan hasil dari pembuatan serbuk instan kunyit putih dan kacang merah dengan jumlah yang berbeda-beda yaitu FI 164 gram, FII 361 gram dan FIII 541 gram.

\section{Hasil Uji Organoleptik}

Sediaan serbuk instan kunyit putih dan kacang merah ini dilakukan uji organoleptik dengan mengamati bau, bentuk, rasa dan warna selama tiga minggu, pengamatan dilakukan setiap tiga hari sekali. Ketiga sampel disimpan di tempat yang sama dengan suhu kamar $\left(15-30^{\circ} \mathrm{C}\right)$. Hasil pengamatan ditulis dalam bentuk tabel. 
Tabel 3. Hasil Uji Organoleptik 3 Hari Pertama

\begin{tabular}{|c|c|c|c|c|}
\hline Formula & $\begin{array}{l}\text { Penga- } \\
\text { matan } \\
\text { Hari } \\
\text { ke- }\end{array}$ & 1 & 3 & 6 \\
\hline I & $\begin{array}{l}\text { Bau } \\
\text { Bentuk } \\
\text { Rasa } \\
\text { Warna }\end{array}$ & $\begin{array}{l}\text { Bau khas kunyit putih } \\
\text { dan kacang merah } \\
\text { Serbuk halus } \\
\text { Manis pahit } \\
\text { Putih agak kecoklat-an }\end{array}$ & $\begin{array}{l}\text { Bau khas kunyit putih } \\
\text { dan kacang merah } \\
\text { Serbuk halus } \\
\text { Manis pahit } \\
\text { Putih agak kecoklat-an }\end{array}$ & $\begin{array}{l}\text { Bau khas kunyit putih } \\
\text { dan kacang merah } \\
\text { Serbuk halus } \\
\text { Manis pahit } \\
\text { Putih agak kecoklat-an }\end{array}$ \\
\hline II & $\begin{array}{l}\text { Bau } \\
\text { Bentuk } \\
\text { Rasa } \\
\text { Warna }\end{array}$ & $\begin{array}{l}\text { Bau khas kunyit putih } \\
\text { dan kacang merah } \\
\text { Serbuk halus } \\
\text { Manis sedikit agak pahit } \\
\text { Putih agak kecoklat-an }\end{array}$ & $\begin{array}{l}\text { Bau khas kunyit putih } \\
\text { dan kacang merah } \\
\text { Serbuk halus } \\
\text { Manis sedikit agak pahit } \\
\text { Putih agak kecoklat-an }\end{array}$ & $\begin{array}{l}\text { Bau khas kunyit putih } \\
\text { dan kacang merah } \\
\text { Serbuk halus } \\
\text { Manis sedikit agak pahit } \\
\text { Putih agak kecoklat-an }\end{array}$ \\
\hline III & $\begin{array}{l}\text { Bau } \\
\text { Bentuk } \\
\text { Rasa } \\
\text { Warna }\end{array}$ & $\begin{array}{l}\text { Bau khas kunyit putih } \\
\text { dan kacang merah } \\
\text { Serbuk halus } \\
\text { Manis } \\
\text { Putih }\end{array}$ & $\begin{array}{l}\text { Bau khas kunyit putih } \\
\text { dan kacang merah } \\
\text { Serbuk halus } \\
\text { Manis } \\
\text { Putih }\end{array}$ & $\begin{array}{l}\text { Bau khas kunyit putih } \\
\text { dan kacang merah } \\
\text { Serbuk halus } \\
\text { Manis } \\
\text { Putih }\end{array}$ \\
\hline
\end{tabular}

Pada Tabel 3. menunjukan bahwa tidak ada perubahan yang signifikan pada sediaan serbuk instan kunyit putih dan kacang merah dalam hal bau, bentuk, rasa dan warna.

Tabel 4. Hasil Uji Organoleptik 3 Hari Kedua

\begin{tabular}{|c|c|c|c|c|}
\hline Formula & $\begin{array}{c}\text { Penga-matan } \\
\text { Hari ke- }\end{array}$ & 9 & 12 & 15 \\
\hline \multirow[t]{4}{*}{ I } & Bau & $\begin{array}{l}\text { Bau khas kunyit putih } \\
\text { dan kacang merah }\end{array}$ & $\begin{array}{l}\text { Bau khas kunyit putih } \\
\text { dan kacang merah }\end{array}$ & $\begin{array}{l}\text { Bau khas kunyit putih } \\
\text { dan kacang merah }\end{array}$ \\
\hline & Bentuk & Serbuk halus & Serbuk halus & Serbuk halus \\
\hline & Rasa & Manis pahit & Manis pahit & Manis pahit \\
\hline & Warna & $\begin{array}{l}\text { Putih agak kecoklat- } \\
\text { an }\end{array}$ & $\begin{array}{l}\text { Putih agak kecoklat- } \\
\text { an }\end{array}$ & $\begin{array}{l}\text { Putih agak kecoklat- } \\
\text { an }\end{array}$ \\
\hline \multirow[t]{4}{*}{ II } & Bau & $\begin{array}{l}\text { Bau khas kunyit putih } \\
\text { dan kacang merah }\end{array}$ & $\begin{array}{l}\text { Bau khas kunyit putih } \\
\text { dan kacang merah }\end{array}$ & $\begin{array}{l}\text { Bau khas kunyit putih } \\
\text { dan kacang merah }\end{array}$ \\
\hline & Bentuk & Serbuk halus & Serbuk halus & Serbuk halus \\
\hline & Rasa & $\begin{array}{l}\text { Manis sedikit agak } \\
\text { pahit }\end{array}$ & $\begin{array}{l}\text { Manis sedikit agak } \\
\text { pahit }\end{array}$ & $\begin{array}{l}\text { Manis sedikit agak } \\
\text { pahit }\end{array}$ \\
\hline & Warna & $\begin{array}{l}\text { Putih agak kecoklat- } \\
\text { an }\end{array}$ & $\begin{array}{l}\text { Putih agak kecoklat- } \\
\text { an }\end{array}$ & $\begin{array}{l}\text { Putih agak kecoklat- } \\
\text { an }\end{array}$ \\
\hline \multirow[t]{4}{*}{ III } & Bau & $\begin{array}{l}\text { Bau khas kunyit putih } \\
\text { dan kacang merah }\end{array}$ & $\begin{array}{l}\text { Bau khas kunyit putih } \\
\text { dan kacang merah }\end{array}$ & $\begin{array}{l}\text { Bau khas kunyit putih } \\
\text { dan kacang merah }\end{array}$ \\
\hline & Bentuk & Serbuk halus & Serbuk halus & Serbuk halus \\
\hline & Rasa & Manis & Manis & Manis \\
\hline & Warna & Putih & Putih & Putih \\
\hline
\end{tabular}

Pada Tabel 4. menunjukan bahwa tidak ada perubahan yang signifikan pada sediaan serbuk instan kunyit putih dan kacang merah dalam hal bau, bentuk, rasa dan warna. 
Tabel 5. Hasil Uji Organoleptik 3 Hari Ketiga

\begin{tabular}{|c|c|c|c|}
\hline Formula & $\begin{array}{c}\text { Pengamatan } \\
\text { Hari ke- }\end{array}$ & 18 & 21 \\
\hline \multirow[t]{4}{*}{ I } & $\mathrm{Bau}$ & $\begin{array}{l}\text { Bau khas kunyit putih dan } \\
\text { kacang merah }\end{array}$ & $\begin{array}{l}\text { Bau khas kunyit putih dan kacang } \\
\text { merah }\end{array}$ \\
\hline & Bentuk & Serbuk halus & Serbuk halus \\
\hline & Rasa & Manis pahit & Manis pahit \\
\hline & Warna & Putih agak kecoklatan & Putih agak kecoklatan \\
\hline \multirow[t]{4}{*}{ II } & $\mathrm{Bau}$ & $\begin{array}{l}\text { Bau khas kunyit putih dan } \\
\text { kacang merah }\end{array}$ & $\begin{array}{l}\text { Bau khas kunyit putih dan kacang } \\
\text { merah }\end{array}$ \\
\hline & Bentuk & Serbuk halus & Serbuk halus \\
\hline & Rasa & Manis sedikit agak pahit & Manis sedikit agak pahit \\
\hline & Warna & Putih agak kecoklatan & Putih agak kecoklatan \\
\hline \multirow[t]{4}{*}{ III } & $\mathrm{Bau}$ & $\begin{array}{l}\text { Bau khas kunyit putih dan } \\
\text { kacang merah }\end{array}$ & $\begin{array}{l}\text { Bau khas kunyit putih dan kacang } \\
\text { merah }\end{array}$ \\
\hline & Bentuk & Serbuk halus & Serbuk halus \\
\hline & Rasa & Manis & Manis \\
\hline & Warna & Putih & Putih \\
\hline
\end{tabular}

Pada Tabel 5. menunjukan bahwa tidak ada perubahan yang signifikan pada sediaan serbuk instan kunyit putih dan

\section{PEMBAHASAN}

Berdasarkan hasil pengamatan dari pembuatan sediaan serbuk instan pada tabel 2. menunjukan hasil dari pembuatan serbuk instan kunyit putih dan kacang merah dengan jumlah yang berbeda-beda yaitu FI 164 gram, FII 361 gram dan FIII 541 gram. Jumlah sediaan berbeda-beda karena dipengaruhi oleh jumlah gula, akan tetapi hasil yang didapat tidak sama jumlahnya dengan jumlah gula yang digunakan karena setelah proses kristalisasi kacang merah dalam hal bau, bentuk, rasa dan warna.

ada beberapa bagian yang menempel pada wajan sehingga jumlah serbuk lebih sedikit.

Berdasarkan hasil pengamatan uji organoleptik sediaan serbuk instan pada tiga sampel selama tiga minggu dengan suhu kamar $\left(15-30^{\circ} \mathrm{C}\right)$, pada tabel 3-5. menunjukan hasil bahwa tidak adanya perubahan yang signifikan dalam hal bau, bentuk, rasa dan warna, hal ini karena proses penyiapan dan pembuatan yang sesuai literatur sehingga tidak menimbulkan hal yang negatif.

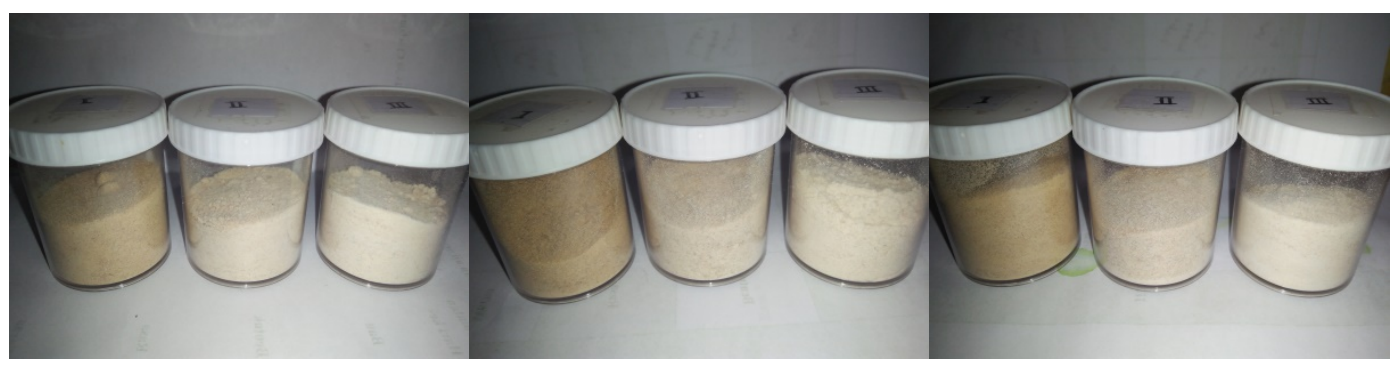

Gambar 4. Uji Organoleptik

Pada gambar 4. menunjukan uji organoleptik selama tiga minggu, tidak adanya perubahan yang signifikan dari sediaan serbuk instan kunyit putih dan kacang merah dalam hal bau, bentuk, rasa dan warna.

Pada tiga formula terdapat perbedaan pada rasa dan warna. Perbedaan rasa pada tiap formula terjadi karena 
perbedaan perbandingan pada gula pasir, semakin banyak gula pasir yang dipakai maka serbuk instan semakin manis, penggunaan gula pasir ini memiliki fungsi sebagai pemanis untuk menutupi rasa pahit kunyit putih, dan fungsi lainnya yaitu membantu proses kristalisasi saat pembuaatan serbuk instan. Pada perbedaan warna dari tiga formulasi terjadi dalam proses pemasakan karena pengadukan yang kurang cepat, jika pengadukan kurang cepat maka sediaan akan sedikit gosong bahkan bisa tidak menjadi kristal. Pada ketiga sampel tersebut terdapat sampel yang cukup enak dan pas, memiliki rasa tidak terlalu manis dan tidak terlalu pahit yaitu pada formula II dengan perbandingan 1:1 (sari $400 \mathrm{ml}$ : gula $400 \mathrm{~g}$ ).

\section{SIMPULAN}

Dari hasil penelitian pembuatan serbuk instan kunyit putih dan kacang merah sebagai antioksidan, hasil uji organoleptik pada tiga sampel tidak menunjukan perubahan yang signifikan, dalam hal bau, bentuk, rasa dan warna. Pada ketiga sampel tersebut terdapat sampel yang cukup enak dan pas, memiliki rasa tidak terlalu manis dan tidak terlalu pahit yaitu pada formula II dengan perbandingan 1:1 (sari $400 \mathrm{ml}$ : gula $400 \mathrm{~g}$ ).

\section{DAFTAR PUSTAKA}

1. Fakriah, et al. (2019). Sosialisasi Bahaya Radikal Bebas Dan Fungsi Antioksidan Alami Bagi Kesehatan. Jurnal Vokasi, 3 (1), pp. 1-3.
2. Pratiwi, Hera. (2015). Analisis Total Fenol Dan Aktivitas Antioksidan Yogurt Ganyong (Canna edulis) Simbiotik Dengan Subsitusi Kacang Merah (Phaseolus vulgaris L). Artikel penelitian, Pp. 1-11.

3. Marliani, L., Budiana, W \& Anandari, Y. (2017). The Effect of Extraction Condition on The Polyphenol Content and Antioxidant Activity of Curcuma zedoaria (Christm.) Roscoe Rhizome. IJPST. 4 (2), PP. 57-64.

4. Ganesan, Kumar \& Xu, Baojun. (2017). Polyphenol-Rich Dry Common Beans (Phaeseolus vulgaris L.) and Their Health Benefits. International journal of Molecular Sciences, 18 (2331), pp. 1-8.

5. Yolandari, Alifia C \& Batubara, Siti C. (2019). Formulasi Minuman Serbuk Instan Mentimun Menggunakan Metode Mixture Design. Journal of Food Technology and Health, 1 (2), pp. 75-76.

6. Gafar, Patoni A \& Maurina, Lancy. (2019). Proses Penginstanan Teтu Lawak, Kunyit Putih dan Jahe Merah serta Pengaruhnya terhadap Kadar Antioksidan dan Daya Terimanya. Prosiding Seminar Nasional II Hasil Litbangyasa Industri, pp. 297-302.

7. Sugiyono. (2015). Metode Penelitian Tindakan (Action Research). Prosiding Seminar Nasional Jurusan PGSD FIP UNP Tahun 2015. 